\title{
Hypercholesterolemia Increases Endothelial Superoxide Anion Production
}

Yuichi Ohara, Timothy E. Peterson, and David G. Harrison

Division of Cardiology, Emory University School of Medicine, Atlanta, Georgia 30322;

and the Atlanta Veterans Administration Medical Center, Decatur, Georgia 30033

\begin{abstract}
Indirect evidence suggests accelerated degradation of endothelium-derived nitric oxide (EDNO) by superoxide anion $\left(\mathrm{O}_{2}^{-}\right)$ in hypercholesterolemic vessels $(\mathrm{HV})$. To directly measure $\mathrm{O}_{2}^{-}$ production by normal vessels (NV) and $\mathrm{HV}$, we used an assay for $\mathrm{O}_{2}^{-}$based on the chemiluminescence $(\mathrm{CL})$ of lucigenin $(\mathrm{L})$. HV ( 1 mo cholesterol-fed rabbits) produced threefold more $\mathrm{O}_{2}^{-}$ than NV (1.47 $\pm 0.20 \mathrm{nM} / \mathrm{mg}$ tissue $/ \mathrm{min}, n=7 \mathrm{vs.} 0.52 \pm 0.05$ $\mathrm{nmol} / \mathrm{mg}$ tissue $/ \mathrm{min}, n=8, P<0.001)$. Endothelial removal increased $\mathrm{O}_{2}^{-}$production in NV $(0.73 \pm 0.08, n=6, P<0.05)$, while decreasing it in $\mathrm{HV}(0.76 \pm 0.15, n=5, P<0.05)$. There was no difference between denuded HV and denuded NV. Oxypurinol, a noncompetitive inhibitor of xanthine oxidase, normalized $\mathrm{O}_{2}^{-}$production in $\mathrm{HV}$, but had no effect in NV. In separate isometric tension studies treatment with oxypurinol improved acetylcholine induced relaxations in $\mathrm{HV}$, while having no effect on responses in normal vessels. Oxypurinol did not alter relaxations to nitroprusside. Thus, the endothelium is a source of $\mathrm{O}_{2}^{-}$ in hypercholesterolemia probably via xanthine oxidase activation. Increased endothelial $\mathrm{O}_{2}^{-}$production in $\mathrm{HV}$ may inactivate endothelium-derived nitric oxide and provide a source for other oxygen radicals, contributing to the early atherosclerotic process. (J. Clin. Invest. 1993.91:2546-2551.) Key words: chemiluminescence $\bullet$ endothelium dependent vascular relaxation • lucigenin • oxypurinol $\bullet$ rabbit aorta $\bullet$ superoxide anion $\bullet$ xanthine oxidase
\end{abstract}

\section{Introduction}

Numerous disease processes, including hypercholesterolemia (1), atherosclerosis (2), ischemia and reperfusion (3), acute or chronic hypertension $(4,5)$, congestive heart failure $(6)$, and diabetes (7), are associated with abnormal endothelium-dependent vascular relaxations. The endothelium-derived vascular relaxing factor $(E D R F)^{1}(8)$, which is now recognized to be either nitric oxide (NO) (9) or a related compound (10), is rapidly destroyed by superoxide radical generating systems such as xanthine/xanthine oxidase (11) or autooxidation of pyrogallol (12), and is protected by superoxide dismutase (SOD) (13).

Recent studies have shown that the production of nitrogen oxides (NO and one-electron oxidation products) from hyper-

\section{Address correspondence to David G. Harrison, M.D., P.O. Box LL, Emory University School of Medicine, Atlanta, GA 30322. \\ Received for publication 5 October 1992 and in revised form 15 January 1993.}

1. Abbreviations used in this paper: EDRF, endothelium-derived relaxing factor; HV, hypercholesterolemic vessels; NO, nitric oxide; NV, normal vessels; $\mathrm{O}_{2}^{-}$, superoxide anion; $\mathrm{SOD}$, superoxide dismutase.

The Journal of Clinical Investigation, Inc.

Volume 91, June 1993, 2546-2551 cholesterolemic and atherosclerotic rabbit aorta is markedly enhanced rather than impaired (14). These findings indicate that the enzyme responsible for production of NO is not impaired by hypercholesterolemia and that there is not a deficiency of substrate or cofactors necessary for NO production. Recently, we also found that the release of biologically active EDRF can be markedly impaired by inhibition of endothelial SOD activity in normal vessels (15), and that treatment with polyethylene-glycolated superoxide dismutase can partially restore impaired endothelium-dependent relaxation of atherosclerotic arteries (16). These data strongly suggest that there is an excess generation of superoxide anion within atherosclerotic vessels. This increased release of superoxide anion may result in accelerated degradation of either nitric oxide or a related component to an inactive form (either $\mathrm{NO}$ to $\mathrm{NO}_{2}^{-}$or $\mathrm{R}-\mathrm{NO}$ to $\mathrm{R}$ - and $\mathrm{NO}_{2}^{-}$).

To test the hypothesis that superoxide anion release is increased by hypercholesterolemia, we used an assay for $\mathrm{O}_{2}^{-}$production from normal vessels and vessels from cholesterol-fed animals based on the chemiluminescence of lucigenin. In additional experiments, we examined the potential role of xanthine oxidase as a source of $\mathrm{O}_{2}^{-}$in vessels of hypercholesterolemic animals.

\section{Methods}

Cholesterol feeding. Male New Zealand white rabbits were randomly assigned to treatment and control groups. Hypercholesterolemia was induced by feeding a $1 \%$ cholesterol diet for 4-6 wk $(n=17)$. Agematched controls $(n=23)$ were maintained on standard rabbit chow.

Detection of chemiluminescence in a cell-free $\mathrm{O}_{2}^{-}$generating system. Chemiluminescence of lucigenin (bis- $N$-methylacridinium nitrate) was detected using a scintillation counter (LS 7000; Beckman Instruments, Inc., Fullerton, CA) in out-of-coincidence mode with a single active photomultiplier tube $(17,18)$. The chemical specificity of this light yielding reaction for superoxide anion has been reported previously (19), and in this study sensitivity and specificity of this assay was determined with xanthine ( $100-400 \mathrm{nM})$ and xanthine oxidase $(0.002$ $\mathrm{U})$ to generate $\mathrm{O}_{2}^{-}$with or without SOD. To assay for $\mathrm{O}_{2}^{-}$, lucigenin $(0.25 \mathrm{mM})$, and xanthine with or without $\operatorname{SOD}(0.5 \mathrm{U} / \mathrm{ml})$ was dissolved in a final volume of $2 \mathrm{ml}$ Krebs-Hepes buffer ( $\mathrm{mM}$ content; $\mathrm{NaCl}, 99.01 ; \mathrm{KCl}, 4.69 ; \mathrm{CaCl}_{2}, 1.87 ; \mathrm{MgSO}_{4}, 1.20 ; \mathrm{K}_{2} \mathrm{HPO}_{4}, 1.03 ;$ $\mathrm{NaHCO}_{3}, 25.0$; Na-Hepes, 20.0 and glucose, 11.1 ; initially gassed with $95 \% \mathrm{O}_{2}$ and $5 \% \mathrm{CO}_{2}, \mathrm{pH} 7.4$ ). This assay solution was placed in glass scintillation vials and counted. Counts were then obtained at 2-min intervals after introduction of xanthine oxidase, and were corrected for background (counts obtained before adding xanthine oxidase).

Combinations of xanthine 50-400 nM and xanthine oxidase 0.002 $\mathrm{U}$ produced transient chemiluminescence signals in a manner dependent on the concentration of xanthine, which were abolished by SOD $0.5 \mathrm{U} / \mathrm{ml}$ (Fig. $1 A$ ).

Determination of $\mathrm{O}_{2}^{-}$yield from xanthine/xanthine oxidase reactions. The reduction of oxygen by xanthine oxidase occurs via both univalent and divalent pathways (20). The percent reduction to superoxide anion (univalent reduction) is dependent on $\mathrm{pH}$ and perhaps other experimental conditions. To determine the degree of univalent 
A

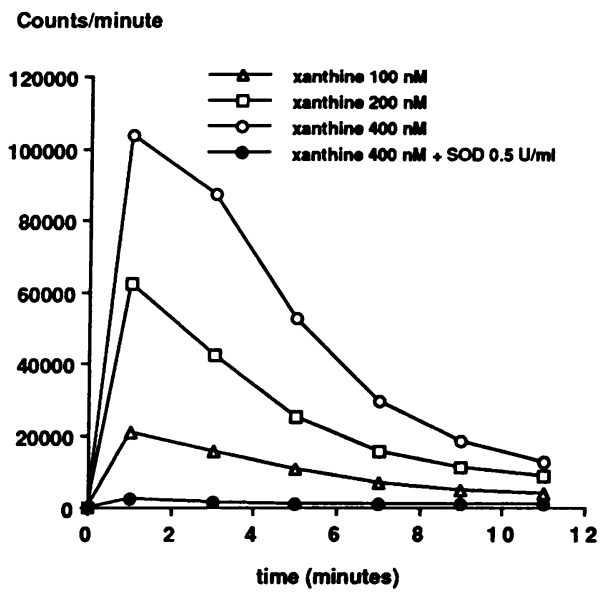

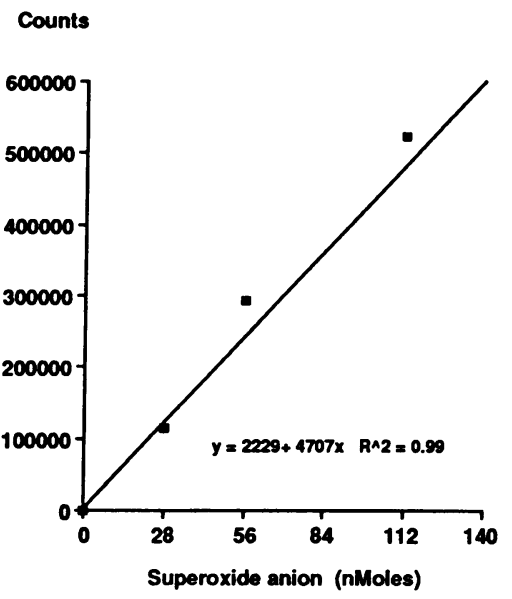

Figure 1. (A) Time course of lucigeninmediated chemiluminescence in response to xanthine (100-400 $\mathrm{nM}$ ) and xanthine oxidase $(0.002 \mathrm{U})$ in the absence or presence of SOD. Similar results were obtained in three other experiments. $(B)$ Correlation between $\mathrm{O}_{2}^{-}$release by xanthine/xanthine oxidase and lucigenin chemiluminescence. There was an excellent correlation between chemiluminescence and $\mathrm{O}_{2}^{-}$production with a simple fit $(r=0.99)$. Similar results were obtained in three other experiments $(r>0.92)$. reduction of oxygen by xanthine oxidase in our experimental conditions, we examined the reduction of ferricytochrome c spectrophotometrically and determined the amount of superoxide anion produced from each mole of xanthine using the formula $\Delta$ absorbance $_{(550 \mathrm{~nm})}$ $=21.1 \times$ concentration $\mathrm{O}_{2}^{-}(21)$. Under the conditions of our assay we determined that yield of $\mathrm{O}_{2}^{-}$was $28 \%$ of the total xanthine present in the reaction. This value was used to calibrate the lucigenin signal obtained during reactions of xanthine and xanthine oxidase. Total luminescence was quantified by integration of the areas under the curves generated in experiments similar to those presented in Fig. $1 \mathrm{~A}$. There was an excellent correlation between chemiluminescence and superoxide anion generated with a simple fit $(r=0.99)$ (Fig. $1 B$ ).

Detection of chemiluminescence elicited by normal and hypercholesterolemic vessels. On the day of the study, rabbits were killed by an overdose injection of pentobarbital. The descending thoracic aorta was isolated and removed, taking care not to damage the endothelium. 5-mm ring segments of thoracic aorta, dissected free of adventitia, were incubated with Krebs-Hepes buffer maintained at $37^{\circ} \mathrm{C}$ for $30 \mathrm{~min}$ and then gently transferred to glass scintillation vials containing $0.25 \mathrm{mM}$ lucigenin and other additions (final volume of $2 \mathrm{ml}$ ). Counts were obtained at 2-min intervals at room temperature. Vials containing all components with the exception of aortic rings were counted and these blank values subtracted from the chemiluminescence signals obtained from the aortic rings.

In preliminary experiments, we found that reaction mixtures without aortic rings did not generate signals above background when observed for times of $\leq 15 \mathrm{~min}$. In other studies, we found that removal of vessel segments from the reaction mixture after 15 min resulted in a rapid decline in signal to background levels.

Lucigenin-mediated chemiluminescence with aortic rings was also measured in the presence of SOD $(6 \mu \mathrm{M})$, catalase $(0.2 \mu \mathrm{M})$, or after 30 min preincubation with mannitol $(10 \mathrm{mM})$ to evaluate the specificity of this reaction.

To assess endothelial $\mathrm{O}_{2}^{-}$production, endothelial removal was performed by gently rubbing the vessels intimal surface with the closed tips of hemostatic forceps.

$\mathrm{O}_{2}^{-}$production of normal and hypercholesterolemic vessels with endothelium preincubated with or without oxypurinol. To examine the potential role of xanthine oxidase as a source of $\mathrm{O}_{2}^{-}$in hypercholesterolemic vessels, we performed an additional series of studies. To perform these experiments, five additional control and five additional cholesterol-fed rabbits were studied. Both normal and hypercholesterolemic vessels were exposed to oxypurinol $(1 \mathrm{mM})$, a noncompetitive antagonist of xanthine oxidase (22) for $30 \mathrm{~min}$ before study. The rings were then washed twice in buffer and then added to scintillation vials containing the lucigenin and buffer as described above.

To determine if oxypurinol could directly scavenge superoxide an- ions, we examined its effect on the lucigenin-mediated chemiluminescence produced by pyrogallol. Lucigenin-mediated chemiluminescence produced by $10 \mu \mathrm{M}$ pyrogallol was assayed in the presence or absence of $1 \mathrm{mM}$ oxypurinol. Chemiluminescence was measured 15 min after exposure to lucigenin as described above.

Isometric tension studies. We also performed additional experiments to determine if $\mathrm{O}_{2}^{-}$produced by xanthine oxidase in the hypercholesterolemic endothelium might impair endothelium-dependent vascular relaxation. Additional normal $(n=5)$, and cholesterol-fed ( $n$ $=5$ ) rabbits were studied. Immediately before death, heparin sulfate $(1,000 \mathrm{U})$ was administered intravenously to prevent blood coagulation. Eight 5-mm ring segments of thoracic aorta were suspended in individual organ chambers $(25 \mathrm{ml})$ filled with Krebs buffer of the following composition: $(\mathrm{mM}) \mathrm{NaCl}, 118.3 ; \mathrm{KCl}, 4.69 ; \mathrm{CaCl}_{2}, 1.87$; $\mathrm{MgSO}_{4}, 1.20 ; \mathrm{K}_{2} \mathrm{HPO}_{4}, 1.03 ; \mathrm{NaHCO}_{3}, 25.0$; and glucose $11.1 ; \mathrm{pH}$ 7.40. The solution was aerated continuously with $95 \% \mathrm{O}_{2} 5 \% \mathrm{CO}_{2}$ and maintained at $37^{\circ} \mathrm{C}$. Tension was recorded with a linear force transducer. Over a period of $1 \mathrm{~h}$, the resting tension was gradually increased and the ring segment was frequently exposed to $80 \mathrm{mM} \mathrm{KCl}$ until the optimal tension for generating force during isometric contraction was reached. The vessels were left at this resting tension throughout the remainder of the study. To prevent the synthesis of vascular prostaglandins, we performed all experiments in the presence of $10 \mu \mathrm{M}$ indomethacin. Four rings were randomly selected to be preincubated with 1 $\mathrm{mM}$ oxypurinol for $1 \mathrm{~h}$. Four other rings were used as control. Oxypurinol was dissolved in DMSO and added into aerated Krebs buffer. Because final concentration of DMSO in organ chamber was $0.5 \%$, the same concentration of DMSO was used for vehicle in control. Vessels were precontracted with L-phenylephrine $(1 \mu \mathrm{M})$. After a stable contraction plateau was reached, all rings were exposed cumulatively to acetylcholine ( $1 \mathrm{nM}-3 \mu \mathrm{M})$. The vessels were washed three times with fresh buffer and allowed to equilibrate for $30 \mathrm{~min}$. The rings were subsequently exposed to nitroprusside ( $1 \mathrm{nM}-3 \mu \mathrm{M})$.

Materials. Acetylcholine chloride, catalase, dimethylsulfoxide, ferricytochrome $c$, indomethacin, lucigenin (bis- $N$-methylacridinium nitrate), mannitol, oxypurinol, L-phenylephrine, pyrogallol, sodium nitroprusside, superoxide dismutase from bovine liver, xanthine, and xanthine oxidase from buttermilk were obtained from Sigma Chemical Co. (St. Louis, MO). Catalase, lucigenin, pyrogallol, superoxide dismutase, xanthine, and xanthine oxidase were dissolved in $50 \mathrm{mM}$ phosphate buffer ( $\mathrm{pH} 7.8$ ) and added into Krebs-Hepes buffer ( $\mathrm{pH} 7.4$ ). Mannitol and oxypurinol were dissolved directly in Krebs-Hepes buffer. In isometric tension studies, oxypurinol was dissolved in DMSO and added into aerated Krebs buffer.

Statistical analysis. Measurements obtained under identical conditions from two ring segments were averaged for each animal. The number of experiments refers to the number of animals. Comparisons of $\mathrm{O}_{2}^{-}$ 
production between normal vessels and hypercholesterolemic vessels were performed using unpaired $t$ test or when appropriate paired $t$ test. The accepted level of significance was $P<0.05$. Data in the figures are mean \pm SEM

\section{Results}

Plasma cholesterol levels. The plasma cholesterol levels were $57 \pm 7$ and $1,270 \pm 180 \mathrm{mg} / \mathrm{dl}$ for the control and cholesterol fed groups, respectively.

$\mathrm{O}_{2}^{-}$generation in normal and hypercholesterolemic vessels with or without endothelium. The chemiluminescence produced by lucigenin was assumed to be dependent on both extracellular and intracellular $\mathrm{O}_{2}^{-}(17,23)$ and increased with time as the lucigenin reached equilibrium with the intracellular space. In normal vessels a plateau of chemiluminescence was attained within 15 min (Fig. 2). Lucigenin-mediated chemiluminescence of aortic rings was also measured in the presence of $6 \mu \mathrm{M}$ superoxide dismutase, $0.2 \mu \mathrm{M}$ catalase, or after $30 \mathrm{~min}$ preincubation with mannitol $10 \mathrm{mM}$. The signals were reduced $71 \%$ by SOD $(n=5, P<0.05)$, but not affected by catalase ( $n$ $=5)$ or mannitol $(n=5)$.

$\mathrm{O}_{2}^{-}$production, estimated by measuring chemiluminescence $15 \mathrm{~min}$ after exposure to lucigenin, was $0.52 \pm 0.05 \mathrm{nmol} /$ $\mathrm{mg}$ tissue (dry wt) per min in normal vessels and was approximately threefold higher in hypercholesterolemic vessels (Fig. 3 ). Endothelial removal increased $\mathrm{O}_{2}^{-}$production in normal vessels (NV) (Fig. 3). In striking contrast, endothelial removal markedly decreased $\mathrm{O}_{2}^{-}$production in hypercholesterolemic vessels ( $\mathrm{HV}$ ) (Fig. 3). Importantly, $\mathrm{O}_{2}^{-}$production by normal and hypercholesterolemic vessels without endothelium was similar.

Effects of oxypurinol on $\mathrm{O}_{2}^{-}$generation in normal and hypercholesterolemic vessels. In hypercholesterolemic vessels, 1 $\mathrm{mM}$ oxypurinol markedly reduced $\mathrm{O}_{2}^{-}$production to a value similar to that observed in normal vessels (Fig. $4 A$ ). Importantly, oxypurinol had no effect on $\mathrm{O}_{2}^{-}$production in normal vessels. The effect of oxypurinol on the production of $\mathrm{O}_{2}^{-}$was

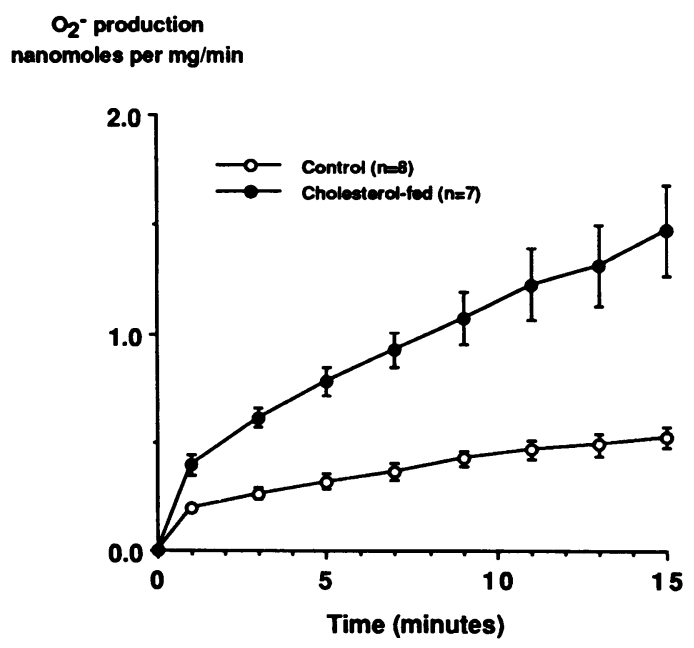

Figure 2. Time course of $\mathrm{O}_{2}^{-}$production estimated by lucigenin chemiluminescence in NV and HV vessels with intact endothelium. Data are expressed as mean \pm SEM of eight normal and seven hypercholesterolemic rabbits. Paired measurements were made under identical conditions on two ring segments and averaged for each animal.

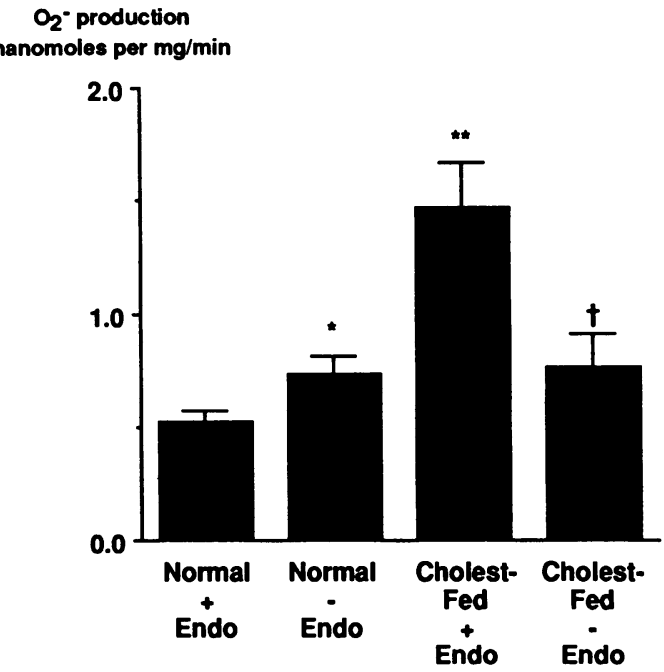

Figure 3. $\mathrm{O}_{2}^{-}$production from $\mathrm{NV}$ with $(+, n=8)$ or without $(-, n$ $=6)$ and HV with $(n=7)$ or without $(n=5)$ endothelium estimated by lucigenin chemiluminescence $15 \mathrm{~min}$ after exposure to lucigenin. The data are expressed as mean $\pm \mathrm{SEM}^{*} P<0.05$ for NV with and without endothelium (paired $t$ test) ${ }^{* *} P<0.001$ for $\mathrm{HV}$ vs. NV with endothelium (unpaired $t$ test) ${ }^{\dagger} P<0.05$ for HV with vs. without endothelium (paired $t$ test).

not related to direct scavenging of the $\mathrm{O}_{2}^{-}$, because oxypurinol did not affect the lucigenin-mediated chemiluminescence produced by autooxidation of pyrogallol (Fig. $4 \mathrm{~B}$ ).

Effects of oxypurinol on vascular responses in normal and hypercholesterolemic vessels. As shown in Fig. 5 A, endothelium-dependent relaxation in response to acetylcholine were markedly impaired in hypercholesterolemic vessels as compared with normal vessels. Oxypurinol did not effect relaxations of normal vessels to acetylcholine. In contrast, in hypercholesterolemic vessels oxypurinol markedly improved relaxations to acetylcholine. Importantly, as shown in Fig. $5 \mathrm{~B}$, this effect was specific for endothelium-dependent vascular relaxation as oxypurinol did not alter relaxations to sodium nitroprusside.

\section{Discussion}

The present study demonstrates that there is an excess generation of $\mathrm{O}_{2}^{-}$within hypercholesterolemic vessels, and that the source of $\mathrm{O}_{2}^{-}$is not the smooth muscle layer but the endothelial cell itself or perhaps monocyte-macrophages (24) closely associated with the endothelium. Interestingly, the endothelium in normal vessels seems to have a protective effect, reducing vascular production of $\mathrm{O}_{2}^{-}$. These findings may explain previous observations regarding the production of nitrogen oxides (NO and one-electron oxidation products of $\mathrm{NO}$, including $\mathrm{NO}_{2}^{-}$) by the endothelium of atherosclerotic rabbits. In our previous study, release of nitrogen oxides, measured by chemiluminescence in the effluent of perfused aortae from hypercholesterolemic and atherosclerotic rabbits, was paradoxically increased (14). The vasorelaxant activity of these nitrogen oxides was markedly depressed, suggesting that they were being released as $\mathrm{NO}_{2}^{-}$. Furthermore, treatment with polyethylene-glycolated SOD can partially restore impaired endothelium-dependent relaxation of atherosclerotic arteries (16). Thus, in aggregate 


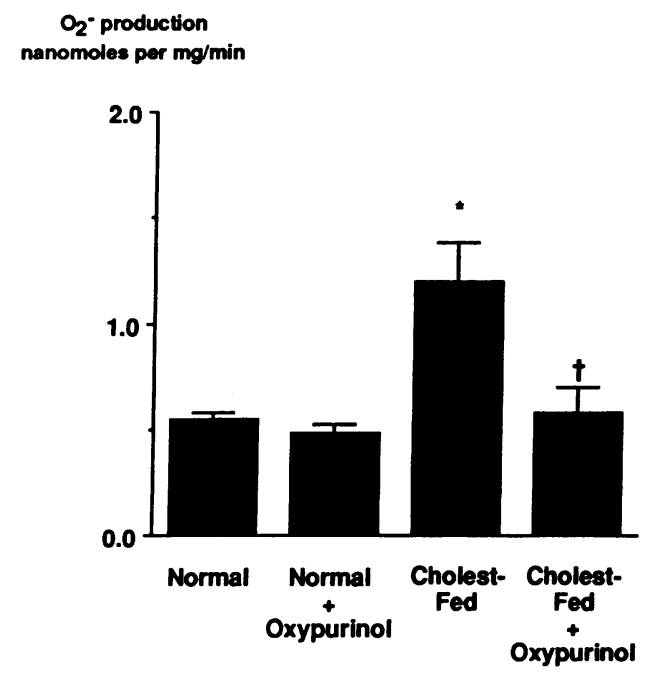

Chemiluminsecence

signal

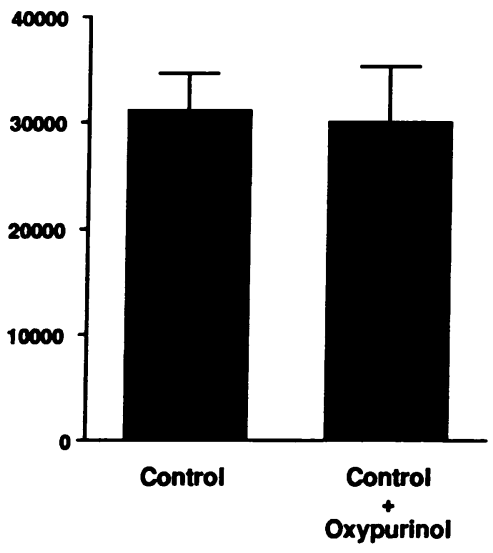

Figure 4. $(A) \mathrm{O}_{2}^{-}$production of $\mathrm{NV}$ and $\mathrm{HV}$ with endothelium preincubated with or without oxypurinol estimated by lucigenin chemiluminescence $15 \mathrm{~min}$ after exposure to lucigenin. Control $(n=5)$ and hypercholesterolemic $(n=5)$ rabbits are separate groups from those indicated in Figs. 2 and $3 .{ }^{*} P<0.05$ (unpaired $t$ test) normal vs. hypercholesterolemic vessels. ${ }^{\dagger} P<0.05$ (paired $t$ test) vessels with and without oxypurinol. ( $B$ ) Lucigenin-mediated chemiluminescence produced by 10 $\mu \mathrm{M}$ pyrogallol with or without $1 \mathrm{mM}$ oxypurinol. Data are expressed as mean \pm SEM ( $n=3$ for both). these findings suggest excess generation of $\mathrm{O}_{2}^{-}$could be responsible for augmented inactivation of EDRF, resulting in impaired endothelium-dependent relaxation in atherosclerotic arteries. The present experiments provide evidence that this hypothesis is correct.

In the endothelium, numerous sources of $\mathrm{O}_{2}^{-}$exist, including prostaglandin metabolism (25), cytochrome p450 (26), electron transport (27), and a process stimulated by protein kinase $C$ (28). Importantly, the endothelium contains xanthine dehydrogenase, which, under a variety of circumstances, can undergo a reversible conversion to xanthine oxidase (29). The mechanisms responsible for conversion of xanthine dehydrogenase to xanthine oxidase are numerous and not completely understood, but include ischemia followed by reperfusion (30), and inflammatory processes mediated by complement C5a or cytokines (31). Our studies with oxypurinol strongly suggest that activation of xanthine oxidase occurs as a result of chronic exposure to hypercholesterolemia. The mechanisms responsible for increased activity of xanthine oxidase in this setting remain unclear.

The present data also indicate that not only is excess xanthine oxidase production responsible for increasing $\mathrm{O}_{2}^{-}$production by the endothelium of hypercholesterolemic vessels, but that the excess $\mathrm{O}_{2}^{-}$may be responsible for altering endothelium-dependent vascular relaxations. Further, these studies may provide insight into why responses to exogenous nitrovasodilators are often normal when endothelium-dependent vascular relaxation are impaired in hypercholesterolemia. Exogenous nitrovasodilators such as nitroglycerin and sodium nitroprusside most likely release nitric oxide within or in close proximity to the vascular smooth muscle, at a site somewhat removed from the endothelial source of superoxide anions.
A

\% RELAXATION

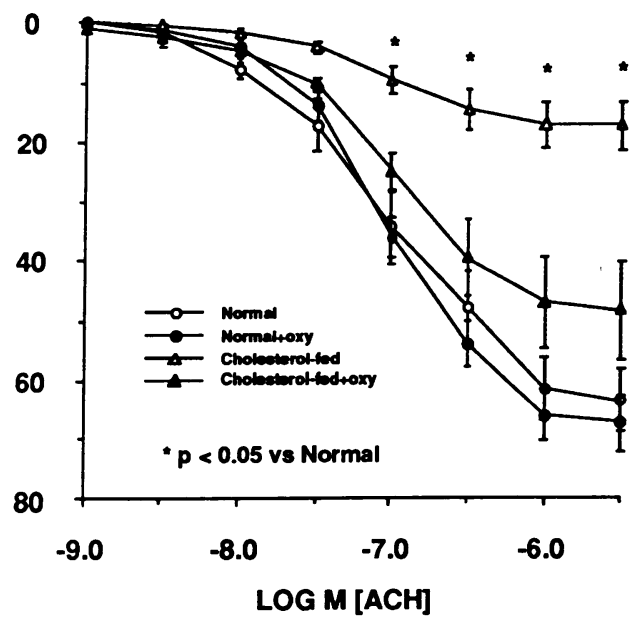

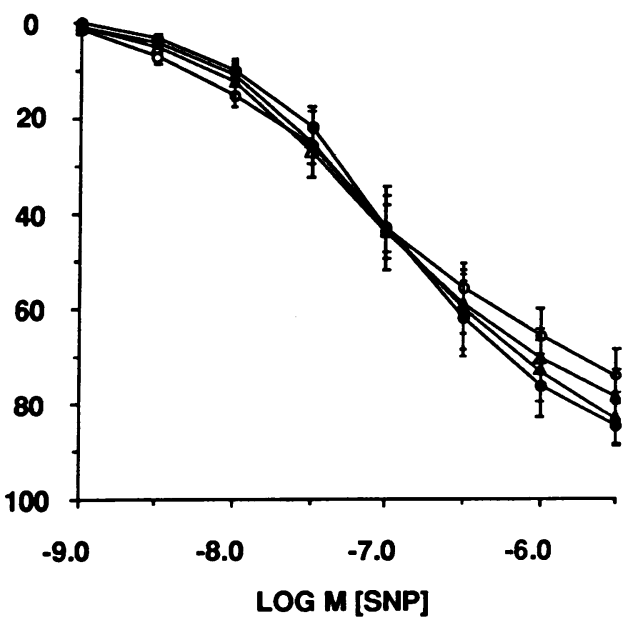

Figure 5. (A) Effects of pretreatment with $1 \mathrm{mM}$ oxypurinol on relaxations induced by acetylcholine $(\mathrm{ACH})$ in aortas of rabbits fed either normal diet or cholesterol-enriched diet. Vascular rings were precontracted with $1 \mu \mathrm{M}$ L-phenylephrine. Phenylephrine contractions were $8.2 \pm 0.4 \mathrm{~g}$ in normal group $(n=5)$, $8.0 \pm 0.6 \mathrm{~g}$ in normal group treated with oxypurinol ( $n$ $=5), 8.6 \pm 0.6 \mathrm{~g}$ in cholesterol-fed group $(n=5)$, and $8.2 \pm 0.7 \mathrm{~g}$ in cholesterol-fed group with oxypurinol ( $n$ $=5$ ). (B) Effects of pretreatment with oxypurinol on relaxation induced by sodium nitroprusside (SNP) in aortas of rabbits fed either normal

diet or cholesterol-enriched diet. Phenylephrine contractions were $7.9 \pm 0.6 \mathrm{~g}$ in normal group $(n=5), 7.7 \pm 0.8 \mathrm{~g}$ in normal group treated with oxypurinol $(n=5), 7.7 \pm 0.4 \mathrm{~g}$ in cholesterol-fed group $(n=5)$, and $7.8 \pm 0.3 \mathrm{~g}$ in cholesterol-fed group with oxypurinol $(n=5)$. Acetylcholine or sodium nitroprusside was given cumulatively. ${ }^{*} P<0.05$ (paired $t$ test) cholesterol-fed animals vs. cholesterol-fed, oxypurinol-treated animals. 
Thus, the nitric oxide released from these agents is more likely to interact with the smooth muscle guanylate cyclase before inactivation by superoxide anions than nitric oxide released from the endothelium, where superoxide anions are apparently being generated.

In the present study, we used lucigenin as a means of detection of superoxide anion. The specificity of this technique has been previously established (19). Lucigenin chemiluminescence is produced by nanomolar concentrations of superoxide anion, but is insensitive to hydroxyl radical and hydrogen peroxide. In preliminary experiments, we examined the possibility that $\mathrm{NO}^{\circ}$ or related compounds could stimulate lucigenin chemiluminescence. The signal obtained from normal vessels was decreased, rather than increased by $3-\mu \mathrm{M}$ solutions of sodium nitroprusside $(n=3)$, and endothelial removal increased, rather than decreased chemiluminescence in normal vessels (Fig. 4). In addition, 1- $\mu \mathrm{M}$ solutions of Angeli's salt (sodium trioxodinitrate), which spontaneously yield nitroxyl anion (32), failed to cause lucigenin chemiluminescence.

Superoxide anion release can also be assessed using a variety of the methods, including spin-trapping techniques (33), luminol chemiluminescence (34), and the reduction of cytochrome $c(35,36)$. Spin-trapping techniques do not readily lend themselves to the study of intact vessels. The chemiluminescence of luminol is highly sensitive, but is not as specific for superoxide anion as lucigenin (19). Finally, the reduction of cytochrome $c$ is quite specific for the superoxide anion, but in preliminary experiments we found it to be less sensitive than the lucigenin technique. In the present experiments, we found lucigenin chemiluminescence to be highly quantitative with regard to superoxide anion production in cell free systems, and to be suitably sensitive for use with intact vessels. A potential criticism of the present work is that the lucigenin chemiluminescence produced by intact vessels was only $71 \%$ inhibited by extracellularly applied SOD. The precise explanation for this remains unclear, but likely relates to the fact that lucigenin produces chemiluminescence based on both intracellular and extracellular superoxide anion production. Because of this, lucigenin chemiluminescence produced by intact vessels or tissue is not completely inhibited by extracellularly applied SOD. Such a phenomenon has been observed in zymosan-activated neutrophils (23) and bovine pulmonary arteries (17).

$\mathrm{O}_{2}^{-}$has been implicated in the oxidation of LDL (37). It is interesting to speculate that increased production of $\mathrm{O}_{2}^{-}$by the endothelium in hypercholesterolemia may further enhance LDL modification and thus lipid accumulation within the vascular wall. $\mathrm{O}_{2}^{-}$also provides a source of other oxygen-centered radicals, such as $\mathrm{H}_{2} \mathrm{O}_{2}$ and ${ }^{\circ} \mathrm{OH}$, which may participate in lipid peroxidation and serve to damage cellular membranes (38). In addition, the $\mathrm{O}_{2}^{-}$may react with $\mathrm{NO}^{\circ}$, which is also produced in excess within the endothelium of hypercholesterolemic animals to produce the highly injurious peroxynitrite radical (39). In these respects, the increase in $\mathrm{O}_{2}^{-}$production in the setting of hypercholesterolemia may not only inactivate endotheliumderived nitric oxide, but may also serve as an early event in the atherosclerotic process.

\section{Acknowledgments}

We acknowledge the assistance of Ann B. Peterson in the preparation of this manuscript. This work was supported by National Institutes of Health grants HL-32717 and HL-39006, and a Merit Grant from the
Veterans Administration. Dr. Harrison is an Established Investigator of the American Heart Association.

\section{References}

1. Jayakody, R. L., M. P. Senaratne, A. B. R. Thomson, and C. T. Kappagoda. 1985. Cholesterol feeding impairs endothelium-dependent relaxation of rabbit aorta. Can. J. Physiol. Pharmacol. 63:1206-1209.

2. Freiman, P. C., G. G. Mitchell, D. D. Heistad, M. L. Armstrong, and D. G. Harrison. 1986. Atherosclerosis impairs endothelium-dependent vascular relaxation to acetylcholine and thrombin in primates. Circ. Res. 58:783-789.

3. Ku, D. D. 1982 . Coronary vascular reactivity after acute myocardial ischemia. Science (Wash. DC). 218:576-578.

4. Lamping, K. G., and W. P. Dole. 1987. Acute hypertension selectively potentiates constrictor responses of large coronary arteries to serotonin by altering endothelial function in vivo. Circ. Res. 61:904-913.

5. Panza, J. A., A. A. Quyyumi, J. E. Brush, and S. E. Epstein. 1990. Abnormal endothelium-dependent relaxation in patients with essential hypertension. N. Engl. J. Med. 323:22-27.

6. Kubo, S. H., T. S. Rector, A. J. Bank, R. E. Williams, and S. M. Heifetz. 1991. Endothelium-dependent vasodilation is attenuated in patients with heart failure. Circulation. 84:1589-1596.

7. Oyama, Y., H. Kawasaki, Y. Hattori, and M. Kanno. 1986. Attenuation of endothelium-dependent relaxation in aorta from diabetic rats. Eur. J. Pharmacol. 132:75-78.

8. Furchgott, R. F., and J. V. Zawadzki. 1980. The obligatory role of endothelial cells in the relaxation of arterial smooth muscle by acetylcholine. Nature (Lond.). 288:373-376.

9. Palmer, R. M., A. G. Ferrige, and S. Moncada. 1987. Nitric oxide release accounts for the biological activity of endothelium-derived relaxing factor. $\mathrm{Na}$ ture (Lond.). 327:524-526.

10. Myers, P. R., R. L. Minor, R. Guerra, J. N. Bates, and D. G. Harrison. 1990. Vasorelaxant properties of the endothelium-derived relaxing factor more closely resemble S-nitrosocysteine than nitric oxide. Nature (Lond.). 345:161163.

11. Rubanyi, G. M., and P. M. Vanhoutte. 1986. Oxygen-derived free radicals, endothelium, and responsiveness of vascular smooth muscle. Am. J. Physiol. 250(Heart Circ. Physiol. 19):H815-H821.

12. Ignarro, L. J., R. E. Byrns, G. M. Buga, K. S. Wood, and G. Chaudhuri. 1988. Pharmacological evidence that endothelium-derived relaxing factor is nitric oxide: use of pyrogallol and superoxide dismutase to study endothelium-dependent and nitric oxide-elicited vascular smooth muscle relaxation. J. Pharmacol. Exp. Ther. 244:181-189.

13. Gryglewski, R. J., R. M. Palmer, and S. Moncada. 1986. Superoxide anion is involved in the breakdown of endothelium-derived vascular relaxing factor. Nature (Lond.). 320:454-456.

14. Minor, R. L. J., P. R. Myers, R. Guerra, J. N. Bates, and D. G. Harrison. 1990. Diet-induced atherosclerosis increases the release of nitrogen oxides from rabbit aorta. J. Clin. Invest. 86:2109-2116.

15. Mügge, A., J. H. Elwell, T. E. Peterson, D. D. Heistad, and D. G. Harrison. 1991. Release of intact endothelium-derived relaxing factor depends on endothelial superoxide activity. Am. J. Physiol. 260(Cell Physiol. 29):C219-C225.

16. Mügge, A., J. H. Elwell, T. E. Peterson, T. G. Hofmeyer, D. D. Heistad, and D. G. Harrison. 1991. Chronic treatment with polyethylene-glycolated superoxide dismutase partially restores endothelium-dependent vascular relaxations in cholesterol-fed rabbits. Circ. Res. 69:1293-1300.

17. Cherry, P. D., H. A. Omar, K. A. Farrell, J. S. Stuart, and M. S. Wolin. 1990. Superoxide anion inhibits CGMP-associated bovine pulmonary arterial relaxation. Am. J. Physiol. 259(Heart Circ. Physiol. 28):H1056-H1062.

18. Omar, H. A., P. D. Cherry, M. P. Mortelliti, T. Burke-Wolin, and M. S. Wolin. 1991. Inhibition of coronary artery superoxide dismutase attenuates endothelium-dependent and -independent nitrovasodilator relaxation. Circ. Res. 69:601-608.

19. Gyllenhammar, H. 1987. Lucigenin chemiluminescence in the assessment of neutrophil superoxide production. J. Immunol. Methods. 97:209-213.

20. Fridovich, I. 1970. Quantitative aspects of the production of superoxide anion radical by milk xanthine oxidase. J. Biol. Chem. 245:4053-4057.

21. Van Gelder, B. F., and E. C. Slater. 1962. The extinction coefficient of cytochrome c. Biochim. Biophys. Acta. 58:593-595.

22. Elion, G. B., A. Kovensky, G. H. Hitchings, E. Metz, and R. W. Rundles. 1966. Metabolic studies of allopurinol an inhibitor of xanthine oxidase. Biochem. Pharmacol. 15:863-880.

23. Melinn, M., and H. McLaughlin. 1987. Nitroblue tetrazolium reduction in lymphocytes. J. Leukocyte Biol. 41:325-329.

24. Weiss, S. J., G. W. King, and A. F. LoBuglio. 1978. Superoxide generation by human monocytes and macrophages. Am. J. Hematol. 4:1-8.

25. Kontos, H. A., E. P. Wei, E. F. Ellis, L. W. Jenkins, J. T. Povlishock, G. T. Rowe, and M. L. Hess. 1985. Appearance of superoxide anion radical in cerebral 
extracellular space during increased prostaglandin synthesis in cats. Circ. Res. 57:142-151.

26. Sligar, S. G., J. D. Lipscomb, P. G. Debrunner, and I. C. Gunsalus. 1974 Superoxide anion production by the autoxidation of cytochrome $\mathrm{P}^{4} 50_{\mathrm{cam}}$. Bio chem. Biophys. Res. Commun. 61:290-296.

27. Loschen, G., A. Azzi, C. Richter, and L. Flohè. 1974. Superoxide radicals as precursors of mitochondrial hydrogen peroxide. FEBS (Fed. Eur. Biochem. Soc.) Lett. 42:68-72.

28. Matsubara, T., and M. Ziff. 1986. Superoxide anion release by human endothelial cells: synergism between a phorbol ester and a calcium ionophore. $J$. Cell. Physiol. 127:207-210.

29. Della Corte, E., and F. Stirpe. 1972. The regulation of rat liver xanthine oxidase. Biochem. J. 126:739-745.

30. Engerson, T. D., T. G. McKelvey, D. B. Rhyne, E. B. Boggio, S. J. Snyder, and H. P. Jones. 1987. Conversion of xanthine dehydrogenase to oxidase in ischemic rat tissues. J. Clin. Invest. 79:1564-1570.

31. Friedl, H. P., G. O. Till, U. S. Ryan, and P. A. Ward. 1989. Mediator-induced activation of xanthine oxidase in endothelial cells. FASEB (Fed. Am. Soc Exp. Biol.)J. 3:2512-2518.

32. Doyle, M. P., S. N. Mahapatro, R. D. Broene, and J. K. Guy. 1988 Oxidation and reduction of hemoproteins by trioxodinitrate. (II) The role of nitrosyl hydride and nitrite. J. Am. Chem. Soc. 110:593-599.
33. Rosen, G. M., and B. A. Freeman. 1984. Detection of superoxide generated by endothelial cells. Proc. Natl. Acad. Sci. USA. 81:7269-7273.

34. Allen, R. C., R. L. Stjernholm, and R. H. Steele. 1972. Evidence for the generation of an electronic excitation state(s) in human polymorphonuclear leukocytes and its participation in bactericidal activity. Biochem. Biophys. Res. Commun. 47:679-684.

35. Babior, B. M., R. S. Kipnes, and J. T. Curnutte. 1973. The production by leukocytes of superoxide, a potential bactericidal agent. J. Clin. Invest. 52:741744.

36. Heim, K. F., G. Thomas, and P. W. Ramwell. 1991. Superoxide production in the isolated rabbit aorta and the effect of alloxan, indomethacin and nitrovasodilators. J. Pharmacol. Exp. Ther. 256:537-541.

37. Steinbrecher, U. P. 1988. Role of superoxide in endothelial-cell modification of low-density lipoproteins. Biochim. Biophys. Acta. 959:20-30.

38. Fong, K. L., P. B. McCay, and J. L. Poyer. 1973. Evidence that peroxidation of lysosomal membranes is initiated by hydroxyl free radicals produced during flavin enzyme activity. J. Biol. Chem. 248:7792-7797.

39. Beckman, J. S., T. W. Beckman, J. Chen, P. A. Marshall, and B. A. Freeman. 1990. Apparent hydroxyl radical production by peroxynitrite: implications for endothelial injury from nitric oxide and superoxide. Proc. Natl. Acad. Sci. USA. 87:1620-1624. 